\title{
Identity in the I-School Movement
}

\section{by John Leslie King}

John Leslie King is dean and professor in the School of Information, University of Michigan, Ann Arbor. Email: jlking<at> umich.edu
$T^{\mathrm{h}}$ he I-School movement is made up of novel academic programs that embrace new intellectual and professional challenges in a world awash in information. I-Schools move beyond traditional programs, while building on the intellectual and institutional legacies of those programs. I-Schools straddle the academy's ancient engagement with information and the contemporary challenges of ubiquitous information affecting all aspects of society. The mix of legacies and contemporary challenges creates a figure-ground problem in which I-School identity emerges and fades. I-Schools have been born in a state of flux, and in most cases have added to that flux through ongoing innovation. There is no rest in this process. The I-School movement is emergent; its equilibrium can only be found in an essential tension among competing visions in a world of rapid technical and social change. ISchool identity is elusive and will remain so for the foreseeable future.

Elusive identity poses a challenge for the ISchool movement. Academic traditions are conservative and do not readily welcome new fields of endeavor that appear to be searching for their center. Hesitancy with respect to identity evokes suspicions of intellectual weakness and lack of purpose. Such suspicion is a handicap in the best of times; it is particularly threatening in an era of budgetary stress. The temptation to forge an identity looms large in the face of such threats, but premature fixation on an identity would deeply damage the I-School movement. The most remarkable thing about the I-Schools is the variety of their origins and the broad embrace of their intellectual interests. Establishment of identity defines what is "not" as well as what "is," and the first casualty of premature identity can be the elimination of future options that are not now foreseen.

From an institutional perspective, I-Schools have arisen in three principal ways: from the repurposing of pre-existing schools; from the merging of pre-existing but disparate academic programs; and from the creation of altogether new programs by hiring faculty primarily from outside the institution. Each brings different challenges at the detailed level of individual personalities and biases, but all three modalities of development show common characteristics in the struggle for identity. The most prominent is the balancing of endowment identity inherited from the founding population of the school (for example, those faculty from the earlier school, from the dominant elements in a merger or early hires) against emergent identity embracing competing visions of the future. This balance is a deep dilemma because both forms of identity can make compelling arguments. Beyond the inherent advantages of incumbency such as "the early settlers get the best land," endowment identity leverages arguments about "building on current strength" and "reaching critical mass" to create and sustain academic excellence. In contrast, and despite the difficulties that new and politically marginal participants face when confronting incumbents, emergent identity can challenge endowment identity 
with the practical question of why it makes sense to have an I-School at all if the only objective is to do the same old things in the same old ways. Every I-School finds itself confronting the catch-22 situation of wanting to look similar to established disciplines in order to legitimate itself in the academy, yet wanting to look different from established disciplines to warrant new school status.

At first glance, this dilemma can be resolved by simply declaring that the I-School is "interdisciplinary." Unfortunately, such a declaration merely invokes the assumption that good intentions will save the day. Of course, I-Schools are interdisciplinary: there would be no coherent advantage in creat- and stay with it, while punishing those who move from topic to topic without a strong underlying rationale, usually grounded in some disciplinary tradition, to justify the moves.

Academic programs in research-oriented institutions are judged by academic promotion processes, especially the awarding of tenure. Promotion decisions are visible to senior academic administrators and to colleagues in other academic programs. Decisions that are seen as weak damage a program's academic legitimacy, which is especially dangerous in the early years of a school's evolution. Legitimacy is tightly coupled to academic identity, but in complex ways (King and Lyytinen, 2004; Lyytinen and King, 2004). Generally, academic identity is derived from a coherent focus on a particular area of intellectual inquiry. Legitimacy is then contextualized by identity in the sense that the academic value and quality of the work done in a given area will be evaluated by standards of reference that have evolved within the area over time.

Strictly speaking, a clear identity is not necessary for establishing legitimacy: work that meets a broad academic standard of reference is likely to be judged by a broad community of reviewers who will say that it is good work, even if they are not sure of its disciplinary identity. For example, the field of general systems theory that emerged in the mid-20th century was accorded considerable respect primarily because it was championed by an array of respected senior individuals who had already established legitimacy in their respective fields (e.g., Ludwig von Bertalanffy in biology, Kenneth Boulding in economics, Anatol Rappaport in game theory, James G. Miller in physiology, philosophy and behavioral science). Yet it is instructive that general

ing an entirely new kind of school based solely on one wellestablished academic discipline. But simply saying that an I-School is interdisciplinary does not make it so, and history has shown that interdisciplinarity is difficult to achieve (Klein, 1990) and even harder to sustain (Campbell, 1969). True interdisciplinarity requires that intellectually diverse faculty members set aside critical, discipline-based assumptions regarding what work is worth doing, how work is to be evaluated and the importance of consistency in the focus of the scholar over time. The I-School in itself is an institutional departure from past disciplinary practice, and it cannot thrive without the willingness of individual faculty members to depart from practices inherent in their previous disciplinary communities. Questions that plague junior faculty in any disciplinary program - what should I work on, where should I publish, how will the senior faculty know if I am successful - are greatly exacerbated in the I-School. The problem can be acute even for tenured, mid-level faculty who have observed over time that the academy tends to reward those who pick a line of work systems theory lived a rather short and disappointing life as an academic discipline. Aspects of it still deeply influence contemporary thought, as seen in growing programs in complex systems and elsewhere, but the effort to create a stable field fell apart when the senior leadership failed to establish a coherent pathway for more junior scholars to follow. Even if general systems theory had survived as a discipline and prospered, it is not clear to many contemporary observers how it would provide a good model for the I-Schools with respect to identity and legitimacy. The emergent I-Schools tend to be somewhat bottom-heavy with junior scholars trying to prove themselves, and the cadre of senior leadership might not be well enough established or cooperative to forge an identity on their reputation alone. School identity is a lack of coherent intellectual focus coupled with the perception (deserved or otherwise) of low academic standards by colleagues and administrators outside the field. Lack of coherency could bring the I-Schools perilously
The most serious downside risk for establishment of I- 
close to the harsh criticism rendered in some academic communities (physics, for example) that a given piece of work is "so bad it's not even wrong." This is a special hazard when the intellectual quality of the work is difficult to determine, and it is hard to figure out what the work is supposed to be about in the first place. At least a pre-established identity helps the critic parameterize the criteria on which the work should be judged. Lack of identity leaves the critic at sea, usually to the detriment of the work being criticized. Once again, invoking the argument that the scholar works in an "interdisciplinary school" does nothing to alleviate this problem: it merely signals that the perceived weakness in the individual's work is attributable to the weakness in the school itself.

This analysis seems to drift to the dismal conclusion that I-School identity is a hopeless quagmire. On the contrary, it is a stimulating challenge that is fully in keeping with the spirit of the I-School movement. Moreover, winning identity and, by extension, legitimacy, is not that complicated a challenge; it is merely a difficult challenge. Success in establishing I-School identity is less a question of what participants in the ISchools think of themselves than it is a question of what those in the I-Schools want others - people outside the I-Schools whose judgment the I-School scholars respect to think of the I-School movement. Until the day that the ISchool movement is sufficiently strong to be self-absorbed and self-referential (a day that the author hopes is a long way off), the objective is to get people outside the I-School world to provide guidance with respect to what they think the ISchools ought to be. This approach is nothing more than an invocation of principles found in Dale Carnegie's masterpiece, How to Win Friends and Influence People, brought up to date and applied to contemporary academics (Carnegie, 1936). A strong identity for the I-Schools cannot be built by deciding what others ought to think and trying to force it on them. It will come most rapidly and successfully when the participants in the I-School movement learn what the world needs from the I-Schools by talking to people out in the world and building on that understanding.

To work, this strategy requires two important contributions from the I-School movement. The first is that each participant in each I-School must be a superior performer. More established academic programs are not going to get out of the way simply because the I-Schools have arrived. Anyone who joins an I-School must expect to work harder, longer and smarter than people in more established disciplinary traditions. The academy at its best is meritocratic, and meritocracies produce winners and losers. The I-Schools have to be the winners; it's that simple. Second, the I-Schools must engage the world as servants of the society that sustains the academy. Ultimately, the success of the I-School movement lies in the success of the academy at large, and the success of the academy depends on proving to the patrons of the academy that their patronage is a good investment. If the I-Schools can do that, the question of what academic administrators and colleagues in other programs think of the I-Schools will take care of itself.

\footnotetext{
For Further Reading

Campbell, D. T. (1969). Ethnocentrism of disciplines and the fishscale model of omniscience. In M. Sherif \& C. W. Sherif (Eds.), Interdisciplinary Relationships in the Social Sciences (pp. 328348). Chicago: Aldine.

Carnegie, D. (1936). How to win friends and influence people. New York: Simon and Schuster.

King, J.L. \& Lyytinen, K. (2004). Reach and grasp. MIS Quarterly, 28(4), 539-551.

Klein, J.T. (1990). Interdisciplinarity: History, theory and practice. Detroit: Wayne State University Press.

Lyytinen, K. and King, J. L. (2004). Nothing at the center? Academic legitimacy in the IS field. Journal of the Association for Information Systems, 55(6), 220-246.
} 